\title{
Geosynthetic Encased Columns Supporting Rail Infrastructure - Perspectives on Research and Case Studies
}

\author{
Erol GULER $^{\mathrm{a}, 1}$, Cihan CENGIZ ${ }^{\mathrm{b}}$, Oliver DETERT ${ }^{\mathrm{c}}$ \\ ${ }^{\mathrm{a}}$ George Mason University, USA \\ ${ }^{\mathrm{b}}$ University of Birmingham, $U K$ \\ ${ }^{\mathrm{c}}$ Huesker Synthetics, Germany
}

\begin{abstract}
Significant investments are being made towards enhancing the reach of the railway infrastructure due to the vast economic benefits it brings. An inevitable consequence of the expansion of the rail network is the soft soil conditions encountered in the alignment. Geosynthetic encased columns (GEC) is a proven ground improvement technology which can be adapted as soil remediation technique for such conditions. In this paper, first an introduction to the concept of GECs will be given. Then the recent advances in the academic research on the GECs will be elaborated. As it is known, earthquakes are one of the most devastating disasters and certainly also have a major effect on transportation infrastructure. In this paper results of shaking table tests to compare ordinary stone columns and GECs behavior under earthquake loading conditions will also be presented. The brief recap of the state of the art on the geosynthetic encased columns including their earthquake behavior will be followed by case studies on three major projects where the site conditions and project requirements will be discussed. The significant benefits of geosynthetic encased columns in relation to project requirements will also be elaborated.
\end{abstract}

Keywords. Geosynthetics, Geosynthetic Encased Column, Railway Embankments

\section{Introduction}

With the increasing volume of trade and ever-growing need for passenger commute, the local governments and state regulators are looking for ways to efficiently and economically transfer goods and people around the globe. Railway is one of the most competitive alternatives to many modes of transportation in terms of economic viability and minimal environmental impact. Within the context of China, the freight transport heavily relied on shipping prior to the rail initiatives and establishment of new lines. Considering China - Europe trade relations, compared to traditional shipping, the average railway transportation distance between China and Europe is less than 9000 $\mathrm{km}$. It has the advantages of faster transportation speed leading to a shorter transportation time (only one-third of shipping), no weather influence, a higher safety factor, and green environmental protection. Compared to air transport, Railway has

\footnotetext{
${ }^{1}$ Corresponding Author, Erol GULER, Sid and Reva Dewberry Department of Civil, Environmental, and Infrastructure Engineering George Mason University 4400 University Drive, MS 6C1 Fairfax, VA 22030 USA; E-mail: fguler@gmu.edu
} 
obvious economic advantages with a freight rate which is only one-fifth of air transport [1]. On the commuter front, since the announcement of China's high-speed railway construction plan in 2004, significant expansion of high-speed rail network has been established with speeds approaching $350 \mathrm{~km} / \mathrm{h}$ [2]. Another potential application of high-speed railways is the utilization of the services to transport not only passengers but also goods over short to medium distances as a competitive alternative to airfreight. For example, the average flight route distance in Europe is around 500-600 km and in such distances high speed railways could be a competitive alternative to air travel [3] which will not only transport goods with a smaller carbon foot print but will also alleviate the congestion in the already busy airports.

Given the vast economic and environmental benefits of railways and the rapid expansion of the railway networks in all parts of the globe, it is important to ensure the stability of the railway infrastructure from an engineering standpoint. Since railways traverse vast distances, it is not always possible to opt for stable subsoil conditions and often times, due to topographic challenges, the railway alignment is planned on deltas with soft soils. Even if the deltas can be avoided in sparsely populated expanses of land over the railway alignment, since most of the goods are transferred from cities that are commonly located near ports and large river beds, engineers unavoidably face unsuitable subsoil conditions. Beyond the subsoil conditions, seismic activity of the site also introduces an additional level of complexity to transportation projects.

Recent advances in civil and geotechnical engineering aimed at alleviating these difficulties provide a solution for safe, economic, and environmentally friendly method of transporting goods and people over long distances. One of the most prominent innovations in this regard are the Geosynthetic Encased Columns (GECs). GECs are a modern improvement of the historical ordinary stone column (OSC) construction methods which was introduced in early 1970s [4]. It is widely known that ordinary stone columns have inherent disadvantages in remediation of soft ground [5]. The most significant drawback of the OSCs is the bulging failure that the column undergoes in soft soil conditions $\left(s_{u}<15 \mathrm{kPa}\right)$. The geosynthetic encasement on the other hand, provide lateral confinement of the granular column constituents to prevent premature bulging failure and in doing so, the column is able to attract a higher percentage of the overburden stresses to alleviate the loads on the circumferential soft soil. Figure 1 illustrates the concept of GECs in regard to transportation applications. The basal reinforcement (depicted by number 2 in Figure 1) above the column head plane is used to prevent punching failure around the proximity of the column heads due to stress concentration. The basal reinforcement also acts as a membrane and conveys the embankment loads to column heads and facilitates soil arching [6]. While the behavior of embankments supported with piles and other inclusions under the action of static loads are well established, little is known about the behavior of the embankment and individual granular columns under dynamic loading conditions.

\section{Geosynthetic Encased Columns - General Principles}

Similar to the conventional end-bearing piled foundation solutions, GEC system supports the vertical loads coming from the superstructure by transferring loads to firm stratum below the soft native soil. According to the German design guideline EBGEO [7], the stability of an entire field of columns can be approximated by calculating the stability of a singular column and the peripheral soft soil surrounding the column. The 
concept is widely known as the "unit cell" approach and it is adopted in design of soft ground remediation works. Figure 2 illustrates a single unit cell surcharged with a vertical overburden pressure $\left(\sigma_{0}\right)$ and the subsequent distribution of internal and external stresses on the column and the surrounding soil.

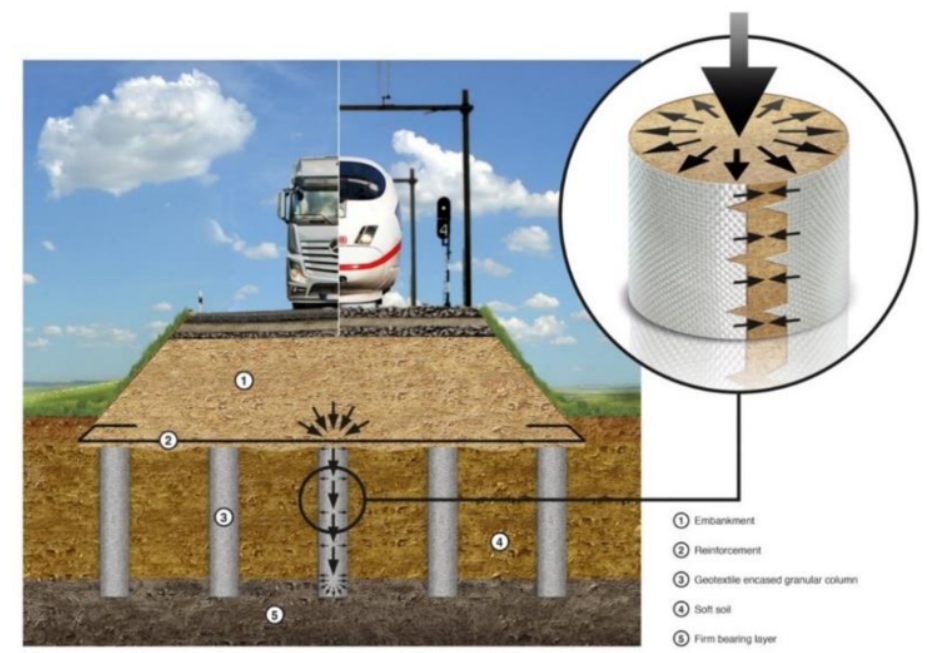

Figure 1. GEC application to support transportation embankments over soft clay strata (HUESKER)

The specific characteristics of the GEC system are:

1. The primary function of the encasement sleeve is the radial confining of the load bearing column to prevent bulging failure.

2. The secondary functions of the reinforcement are separation and filtration which enables the encased column to act as a mega drain. The constituents of the granular column are protected against soft clay ingress by the encasement.

3. As opposed to conventional piled embankments, the system is not completely settlement-free; rather the system self-balances with some settlements occurring for activation by widening of columns and compression of the column material.

4. Given the rather low levels of bearing capacity of the soft soil, the amount of skin friction that can be mobilized is minimal. Therefore, the GEC is typically an end-bearing element transferring the loads to a firm underlying stratum.

5. The GECs are water-permeable; they practically do not influence the flow of groundwater streams, which has potential ecological advantages.

6. The geotextile encasement is a key bearing / reinforcing element, capable of meeting high quality engineered design standards and specifications.

7. It is strongly recommended to install horizontal geosynthetic reinforcement on top of the GECs (at the base of the embankment). The horizontal reinforcement is used for general stability, for transferring spreading forces or to facilitate load transfer into the columns, as well as to compensate for settlements

As illustrated in Figure 2, the geosynthetic encased column attracts a higher percentage of the vertical loads upon itself. Load transfer into the GEC's is achieved by the formation of stress arches in the cover fill. Recent advances in the design of piled embankments have demonstrated the presence of concentric arches theory where it has been shown that the stresses within the embankment are attracted by the stiffer column 
heads. An illustration of the concentric stress arches is given in Figure 3 [8]. Resultant flexible, self-regulating load bearing behavior means that if the columns yield, the load is redistributed to the soft stratum, thereby increasing the ground resistance supporting the columns, which in turn leads to load redistribution back into the columns.

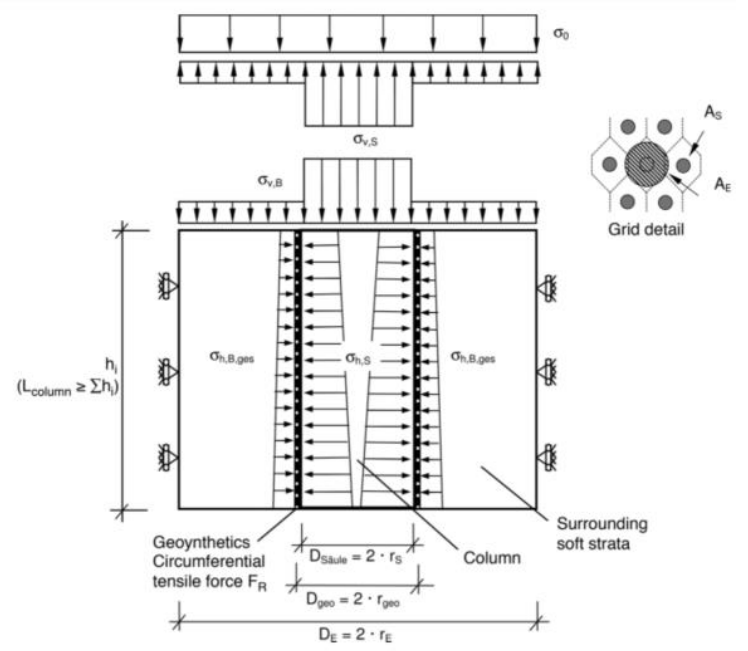

Figure 2. Distribution of stresses according the EBGEO, [7]

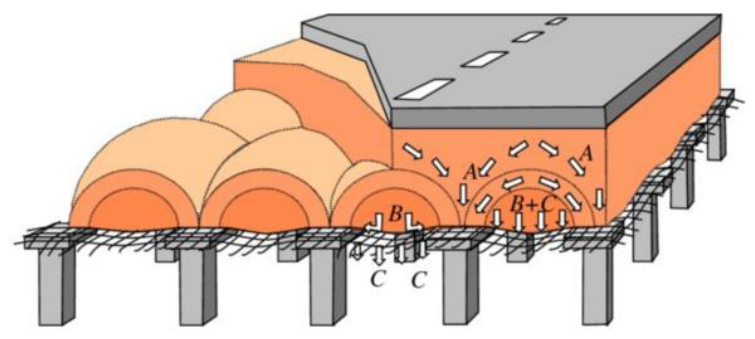

Figure 3. Sketch indicating the stress attraction on column/pile heads [8]

The design of the horizontal reinforcement layer above the column head plane is governed by the relative stiffness ratios of the soft peripheral soil $\left(\mathrm{k}_{\mathrm{s}}\right)$ and the GEC $\left(\mathrm{k}_{\mathrm{s}, \mathrm{T}}\right)$. It is stated that for $\mathrm{k}_{\mathrm{s}, \mathrm{T}} / \mathrm{k}_{\mathrm{s}} \leq 50$ design for horizontal geosynthetic is not necessary and for $\mathrm{k}_{\mathrm{s}, \mathrm{T}} / \mathrm{k}_{\mathrm{s}}>75$ a design is necessary [7]. In-between these values a design is recommended but not necessary.

The installation methods of encased columns are similar to those of the conventional stone columns where displacement method is used for most cases with extremely soft soils [9] as depicted in Figure 4. In displacement method, a closed-tip steel pipe is driven down into the soft soil followed by the insertion of the circular weave geotextile (Figure 5) and sand or gravel backfill. The tip opens, the pipe is pulled upwards under optimized vibration designed to compact the column [9]. Replacement method could also be used for granular column installation in which case excavation of the soft soil inside the pipe is necessitated. This method uses an open ended pipe driven into the ground. Remaining soil in the pipe is removed with specialist tools like an auger during or after driving the pipe. The rest of the operation 
is identical to the displacement method. The excavation method is likely to be preferred with soils with some layers of high penetration resistance or when vibration effects on nearby buildings and infrastructure installations have to be minimized. The advantage of the displacement method compared to the excavation method is based on the faster and more economical column installation and the effects of pre-stressing the soft soil. Furthermore, it is not necessary to excavate and dispose soil. The excess pore water pressure, the vibrations and deformations have to be considered [9]. Figure 6 illustrates the replacement method.

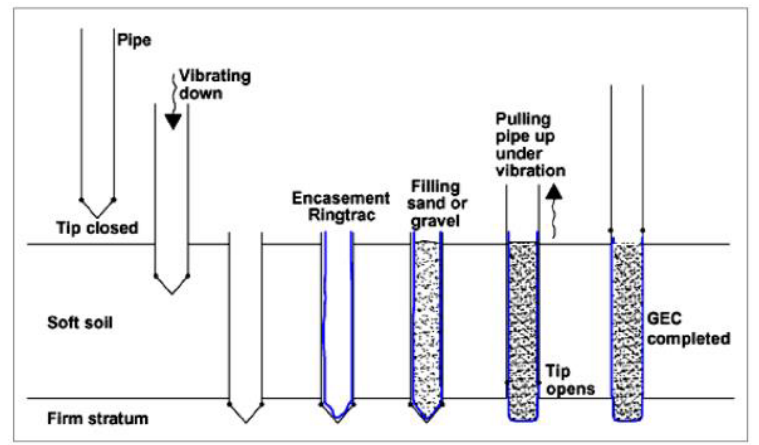

Figure 4. Displacement method of construction [9]
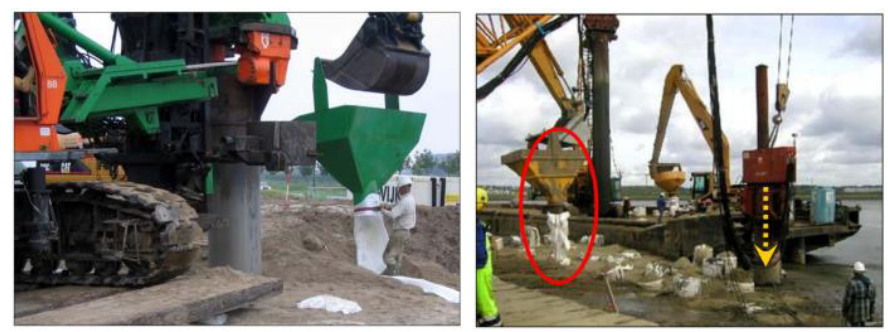

Figure 5. Installation of geotextile encasement [9]

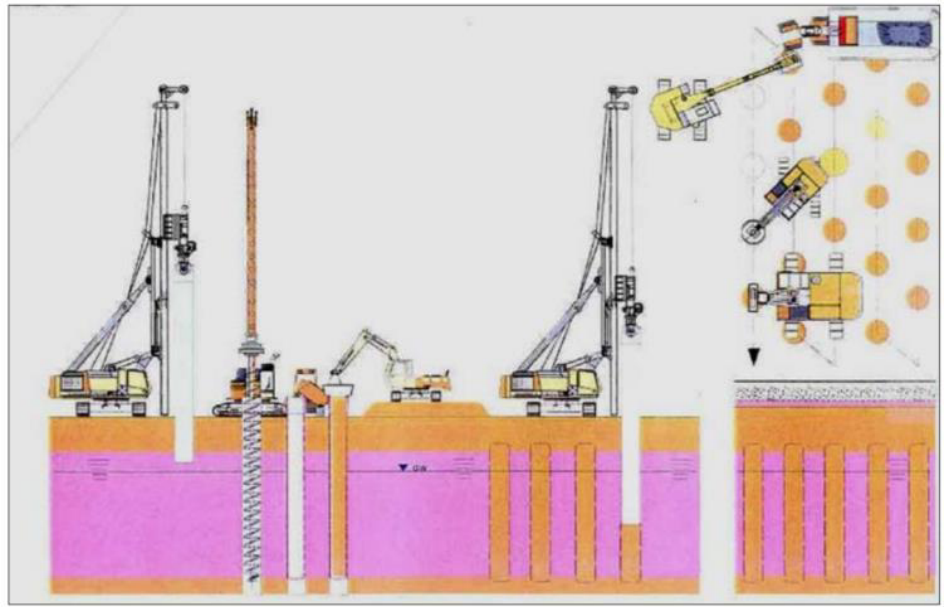

Figure 6. Sketch illustrating replacement method [9] 
The designing for GEC supported foundations can be best explained by pre-design charts. In order to produce such charts the exemplar case illustrated in Figure 7 might be considered. The loading considered for the example consists of $6,10 \& 14 \mathrm{~m}$ high embankments with a bulk unit weight $(\gamma)$ of $19 \mathrm{kN} / \mathrm{m}^{3}$, constructed on $10 \mathrm{~m}$ deep homogenous foundation soil. The ground water level is equal to the level of the natural ground surface. The key deformation parameter of the soft subsoil, the oedometric (constrained) modulus $\left(\mathrm{M}_{\mathrm{ref}}\right)$ is assumed to be equal to $0.5 \mathrm{MPa}$ and $1.0 \mathrm{MPa}$ for a reference stress of $100 \mathrm{kPa}$. The Poisson's ratio $(v)$ is taken as 0.4 . Three different "percentages" of area replacement ratios of columns are analyzed: 10, 15 and 20\%. Columns $800 \mathrm{~mm}$ in diameter are considered in the foundation soil, filled with a compacted sand with an effective angle of internal friction $\left(\varphi^{\prime}\right)$ of $30^{\circ}$ and submerged bulk unit weight $\left(\gamma^{\prime}\right)$ of $9 \mathrm{kN} / \mathrm{m} 3$. A range of tensile stiffness moduli $\mathbf{J}$ varying from 1000 to $4000 \mathrm{kN} / \mathrm{m}$ were analyzed, although the most common range of short- and long-term moduli of the encasement is 2000 to $6000 \mathrm{kN} / \mathrm{m}$. The diameter of encasement is chosen to be equal to the diameter of the installation steel pipe. The results (only in terms of settlement due to space limitation) are shown as graphs in Figures 8. They are presented with the settlements on top of GEC on the Y-axis, the tensile modulus $\mathrm{J}$ on the $\mathrm{X}$-axis, and the differing percentage of replacement ratios $(10$, $15 \& 20 \%$ ), grouped on the same graph. Above each graph the embankment height and the reference oedometric (constrained) modulus $\mathrm{M}_{\text {ref }}$ of soft soil are cited [10].

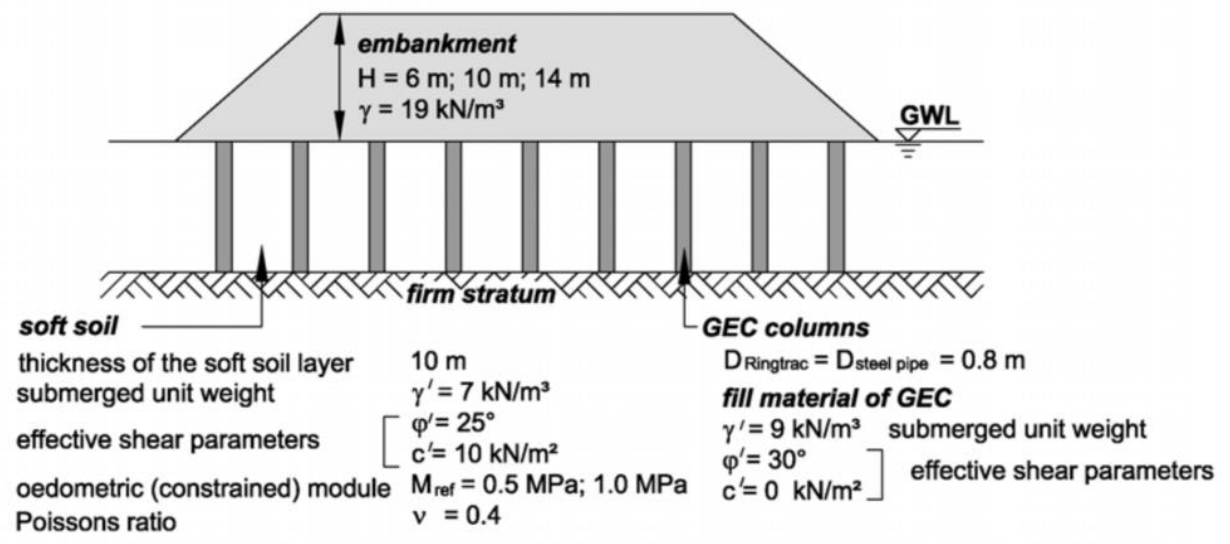

Figure 7. Overview of the system analyzed for the charts [10]

The plots in Figure 8 provide an "engineering feeling" about the possibilities of the GEC system within the context of the exemplar case analyzed. The curves in Figures 8 clearly demonstrate the role of the tensile stiffness $(\mathrm{J})$ as a very significant parameter on the settlement of the system. For example, GECs with a ring tensile module of 4000 $\mathrm{kN} / \mathrm{m}$ can reduce the settlement more than 2 times compared to lower moduli encasement. Analyses not shown herein result in an even stronger influence of tensile module for softer subsoils. On the contrary, for a subsoil with twice the stiffness the influence is in generally slightly less strong, but still very significant. The tendency can be identified comparing the plots in Figure 8. More details and graphs can be found in Alexiew et al. (2003) [11]. A combination of high tensile moduli and high percentage of GEC can reduce the settlement more than 3 times compared to low moduli and percentage. Note, that the increase of encasement tensile modulus influences the settlement more significantly than the increase of GEC percentage. In many cases, 
more than one combination of tensile modulus and GEC percentage can be used to achieve a required reduction of settlement. In this context, one should keep in mind that a higher percentage of GEC leads not only to use more geosynthetic material, but to a disproportionately large additional construction time and/or installation effort in terms of equipment, labor etc. Based on the present experience, it is usually more efficient to choose higher moduli of encasement than higher percentage of columns.

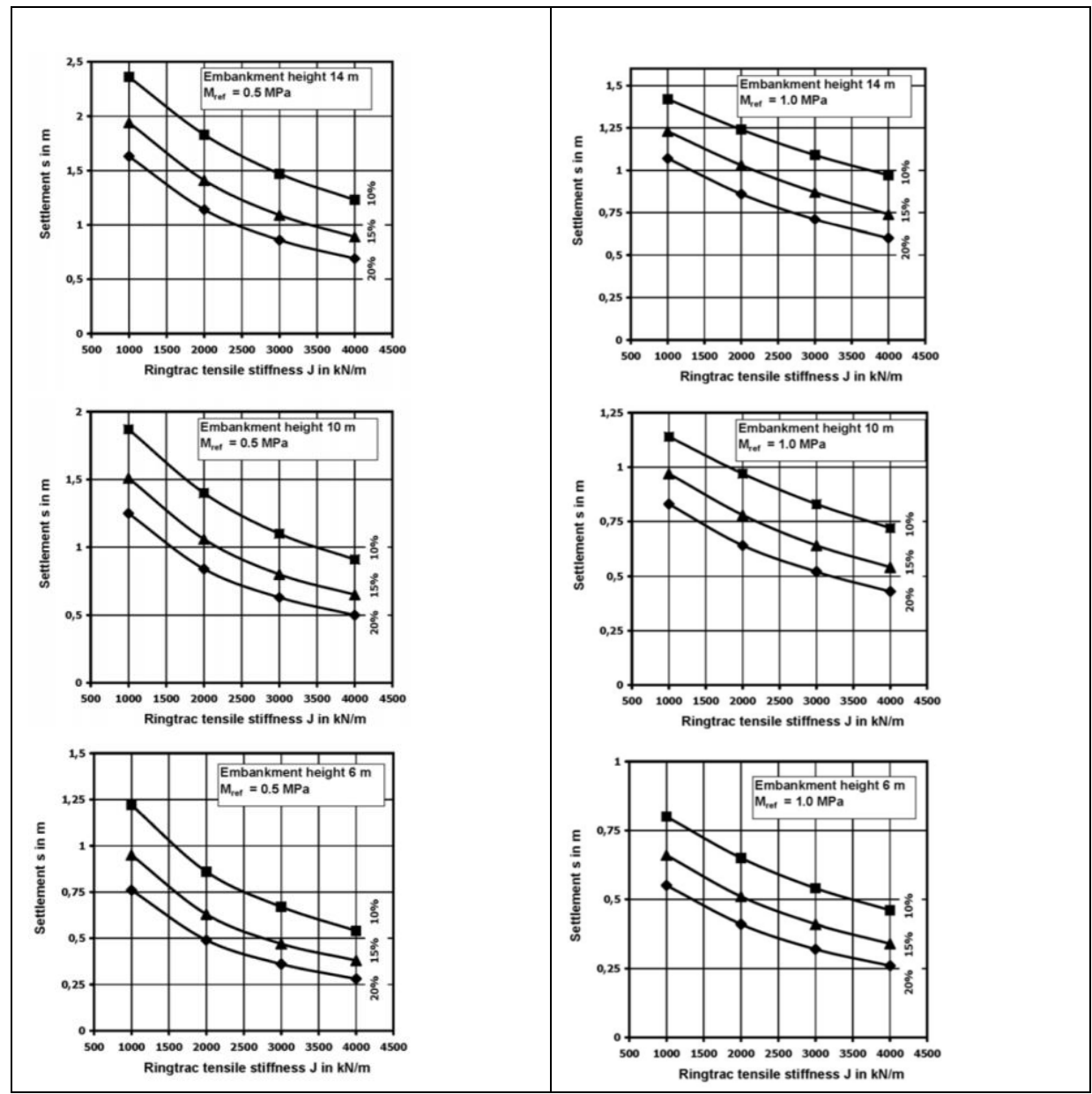

Figure 8. Settlements vs. tensile modulus of encasement for $M_{r e f}=0.5$ (left) and $M_{r e f}=1$ (right) $M P a(N B$ : The modulus is time-dependent) [10]

\section{Research on the Granular Columns and Column Supported Soft Soils}

Earliest accounts of research on ordinary stone columns can be traced back to the pioneering study of Hughes et al., [4] where the field performance of stone columns were investigated in 1970s. Following on from this study, where only static vertical loads were considered, Engelhardt and Golding [12] acknowledged as early as 1975 that further research is necessary to determine the behavior of the individual granular 
columns and the column treated soft soil under dynamic/seismic loading conditions. Although the need to determine the seismic behavior of soft soil deposits enhanced by granular columns were accurately identified by early research, vast majority of the literature on encased and ordinary granular columns remained related to the behavior of columns under static vertical loads [13]. A thorough understanding of the granular column behavior under dynamic loads is needed for robust and safe designs of transportation embankments.

\subsection{State of the Art - Static Load Considerations}

Today, the behavior of both OSCs and GECs under the action of static vertical loads are reasonably well understood. The literature on granular columns can be divided into three broad categories in terms of the methods used to investigate their loaddeformation characteristics namely, physical, numerical, and analytical models. Within the physical models category, small-scale laboratory work has been conducted to investigate the behavior of granular columns. The abundance of small-scale experimental work focusing on the bulging depth and stress concentration ratio of granular column behavior has contributed to a well-established understating of column response. Especially, triaxial type experimental apparatus [14, 15] and variations thereof [16] have been utilized due to the relative ease, widespread availability, and the physical resemblance of the apparatus to that of an idealized unit cell. The main findings of the triaxial test apparatus based studies is the bearing capacity increase or the settlement reduction achieved by OSC and GEC addition. Other small-scale laboratory work include 1-g testing of scaled granular columns and group of columns under simulated footing loads $[5,17]$ where bulging characteristics of model columns are investigated. The common consensus in the small-scale 1-g tests is the critical bulging depth for OSCs and GECs are 2D [18] and 3D [19], respectively.

Although small-scale laboratory research has provided valuable information on the behavior of the granular columns, in order to avoid the scaling issues, researchers [20, 21] have opted for large-scale tests to study the behavior of granular columns at large scale. In the large-scale studies, the stress concentration ratio of for granular columns have been reported at a wide range between 3 and 20. This range of course, reflects the variability in peripheral soil conditions, and vast difference in reinforcement stiffness and column fill materials between different experimental approaches.

Field scale studies conducted by Marcio et al. [22] have revealed significant information on the behavior of GECs especially in terms of stress concentration ratios which was reported to be in the range of 2 to 3 . The range of the stress concentration ratios reported in the literature vary within a very wide range and the findings of a controlled field test is deemed to be important in that regard. In other field tests, it was demonstrated that GECs can be utilized as pressure-relief systems in bridge abutments [23]. The study concluded that GECs reduced up to $50 \%$ of the horizontal earth pressure over bridge border foundation piles when compared to values predicted for unreinforced ground. Full-scale tests conducted by Yoo and Lee [24] have shown that the maximum tensile stress occurred at a depth of $\mathrm{D}$ (one-column-diameter) below the column head plane suggesting that the bulging depth was found to be at a depth of D for field conditions. It is also suggested that the partial encasement length should at least extend to a depth of 4D in order to mitigate the bulging failure of the column.

Numerical modelling of embankment sections supported by GECs have shown that settlement reduction increased for GECs with a higher reinforcement stiffness and a 
critical partial reinforcement length (dependent on clay depth) is required to arrest settlements [25]. While finite elements models have provided valuable insight into granular column behavior, discrete element modelling (DEM) studies have shown the interactions between the granular column constituents, reinforcement, and the surround soft soil [26]. DEM models have also numerically demonstrated that the movement of the column was constrained by the geosynthetic encasement at shallow depth and was limited by the confining stress of the surrounding soil at greater depth [27]. Numerical studies have also demonstrated that the stress concentration factors could be as great as 50 given that the soft soil is coupled with a stiff column [28].

Beyond the physical and finite element modelling approaches, analytical models have been used to calculate and design granular columns and GECs. Early methods of approximate analytical solutions assumed an infinitely wide uniformly loaded field of regularly spaced stone columns and the calculations were based on axisymmetric assumptions [29]. As the validity and the apparent simplicity of these approaches were proven, the use of unit cell concept was widely applied and led to one of the most widely used iterative calculation approach for GEC design. In this respect the pioneering analytical model set forth by Raithel and Kempfert [30] has inspired the calculation methods in design guidelines such as EBGEO [7] and further extensions and modifications were made to the calculation model to form analytical closed-form elasto-plastic solutions [31] where the elasto-plastic behavior of the column material with confined yielding according to the Rowe stress dilatancy theory [32] was considered.

While the vertical load-settlement behavior is studied by a vast amount of the available literature, very limited studies exist in modelling the shear resistance of granular column enhanced unit cells. One of the notable physical modelling attempts on determining the shear resistance of granular and geosynthetic encased unit cell columns was conducted by Mohapatra et al. [33] where a conventional large-scale direct shear apparatus was used. Further, on a follow-up study, Mohapatra et al. [34] utilized ABAQUS to further probe into the behavior of granular columns and modelled the shear resistance behavior of OSCs and GECs. These tests and numerical models demonstrated the presence of different failure mechanisms for OSCs and GECs. While OSCs yielded in a distinct plane (coincident with the shear/slip plane), GECs with stiff reinforcements exhibited a local buckling behavior around the slip plane. GECs with smaller reinforcement modulus on the other hand, failed by rupturing of the reinforcement in close proximity to the failure plane. Cengiz et al. [35] designed and developed a bespoke unit cell device to accurately model the shear resistance behavior of granular column enhanced unit cells. The device allowed for the proper scaling of the granular column geometry in terms of height to diameter ratios and allowed for the use of construction material that are representative of field applications. The experimental program demonstrated that the vertical strains occurring on the reinforcement were significantly larger than that of the circumferential strains and this disparity (which is typically not considered in design guidelines) may lead to premature failure of the columns by rupturing of the reinforcing in length-wise direction.

The literature survey presented above on the behavior of granular columns under static loading conditions, briefly highlights the important research on granular columns. Extensive summary of scientific work conducted on granular columns can be found in two recent state of the art papers [36, 37]. 


\subsection{Recent Studies on the Response of Columns to Dynamic Excitations}

While there is an abundance of available works on the behavior of the ordinary and encased columns under vertically applied static load conditions, there are very few studies on the dynamic behavior of granular columns with the notable exception of the recent study of Yoo and Abbas [38]. In fact, granular columns can be subjected to vertical and lateral loads, moments and combinations of these loads under transient conditions. Moreover, the nature of the loading on a group of columns is not necessarily characterized by static loads. Cyclic and seismic loads can be imposed on a field of columns by the actions of machine foundations, traffic, and earthquakes [39]. In light of the above, the present contribution aims to summarize the results of a series of physical modelling research on granular columns under dynamic loads [35, 40-43]. The physical modelling endeavor utilized a laminar box apparatus to simulate free-field conditions for the model tests whereby recurring reflection of the seismic waves are prevented. Figure 9 illustrates the experimental model layout with the instrumentation detail.
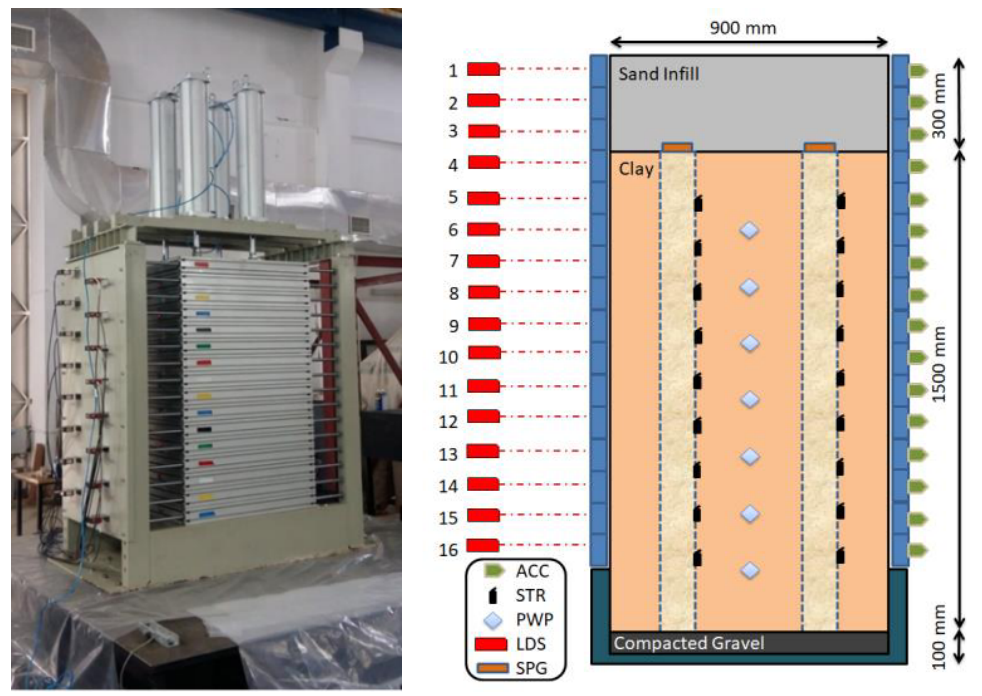

Figure 9. Photograph and a vertical cross-section of the experimental setup (ACC: Accelerometer, STR: Strain Rosette, PPT: Porewater pressure gauge, LDS: Laser Displacement Sensor, SPG: Soil Pressure Gauge) redrawn after [39]

The experimental assembly is subjected to earthquake excitations with a uniaxial shaking table. The laminar box has inner clearances of $900 \times 900 \mathrm{~mm}$. The height of the samples that can be accommodated in the laminar box is $1932 \mathrm{~mm}$. A $300 \mathrm{~mm}$ deep rigid base cavity underlay the laminates. The laminar box consists of 16 individually supported laminate which are made up of aluminum sigma profiles [41, 43]. A vertical clearance of $2 \mathrm{~mm}$ is provided between the laminates to facilitate independent movement of the laminates under the action of seismic excitations. The soft clay bed is consolidated in the laminar box to mimic the soft soil conditions encountered in the field. Commercially available kaolinite clay is used to form clay beds with an undrained shear strength $\left(s_{u}\right)$ of about $7 \mathrm{kPa}$. Upon completion of consolidation OSCs constituted from poorly graded gravel material and GECs were installed in the soft clay bed with displacement method. Two different reinforcement materials were used to 
encase the GECs, namely, Sefitec and Stabilenka supplied by Huesker GmbH with professional stitching to conform with the diameter of the model columns at $136 \mathrm{~mm}$. The engineering properties of the reinforcement materials were determined in accordance to ISO 10319 [44]. The reinforcement stiffnesses were 400 and $1000 \mathrm{kN} / \mathrm{m}$, respectively. These reinforcements shall henceforth be designated as J400 and J1000. Once the granular columns were installed, the laminar box was topped off with sand infill material to resemble an embankment. The experimental program consisted of four models:

1. The clay bed with no column enhancement, designated as Clay-Benchmark

2. Clay bed improved with four $136 \mathrm{~mm}$ diameter OSCs, designated as OSC

3. Clay bed improved with four $136 \mathrm{~mm}$ diameter GECs with J400 reinforcement

4. Clay bed improved with four $136 \mathrm{~mm}$ diameter GECs with J1000 reinforcement

The models prescribed above were excited with five different earthquake input motions which are 25\%, 50\%, and 100\% amplitude El-Centro record and 50\% and 100\% Kobe event. The experimental models were also excited with sinusoidal waveforms to extract hysteresis loops.

One of the key findings of the experimental program highlighted the beneficial effects of GEC installation in stabilizing soft soils against seismic excitations. The lateral deformation of the soft clay profile at the base and at the topmost layer is indicative of the soil behavior under dynamic loading conditions. The lateral deformation behavior of the experimental models are illustrated in Figures 10 and 11. In Figure 10, the maximum lateral deformations made by the base layer of the laminar box is illustrated. The inertial movements of the soil body under the action of various input motions are restricted by the stiffness of the entire soil-granular column system. Therefore, it could be expected that stiffer soil profiles will move as a coherent body while lower-stiffness profiles will deform as individual horizontal layers. In the semi logarithmic plots of the "base drift" curves, it is seen that the presence of the GECs hold the soft soil body as a coherent unit and the basal displacements are more pronounced in GEC enhanced soft soil columns. Unenhanced (benchmark) clay bed and OSC enhanced clay bed on the other hand do not undergo appreciable lateral deformations at the base of the soil profiles.

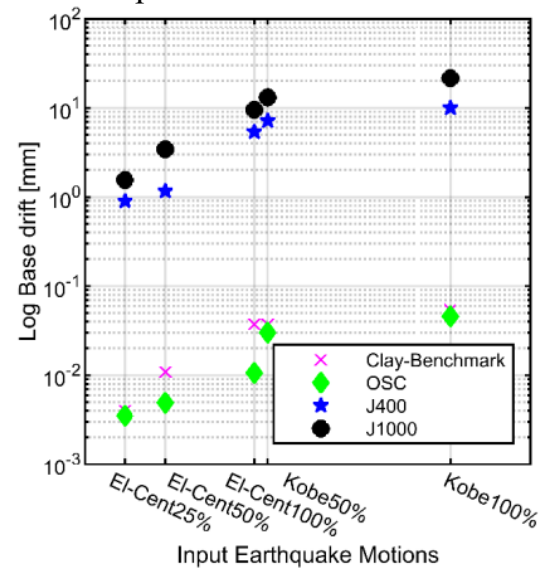

Figure 10. Bottom-most layer maximum lateral displacements for the experimental models under various seismic loading demands 
Figure 11 illustrates the lateral displacement of the topmost soil layer for soil profiles in a similar fashion to that of Figure 10. Contrary to the findings of Figure 10, the GEC installed soil profiles seem to undergo significantly smaller lateral displacements than that of benchmark model and the OSC enhanced model. For instance, under $100 \%$ El-Centro loading, the maximum lateral deformation for $\mathrm{J} 1000$ is about $50 \mathrm{~mm}$ whereas the same value for benchmark model is about $150 \mathrm{~mm}$. Similar trends have been observed throughout the loading stages in the experimental program as depicted in Figure 11. These findings combined with the large lateral deformation demand on GEC installed clay beds point out to a reduced displacement and shear strain profile within the GEC enhanced soft soil beds. The ramifications of these findings for the soft soil is the reduced shear strain amplitudes which leads to smaller shear modulus degradation due to repeated loading. Similarly, it could be said that due to the limited amount of shear strain flux generated within the soft clay body, the survivability of utilities and lifelines present in the soft clay and the transport infrastructure supported by the soft clay layer significantly increases. This is to say that given the proposed soft soil strata is in a seismically active zone, presence of GECs within the underlying foundation soil can significantly increase the performance of the transportation infrastructure under the action of dynamic loads. Combined with the widely known beneficial effects of granular column such as increased drainage, this foundation system presents itself as a viable method to remediate soft soils also in seismic design.

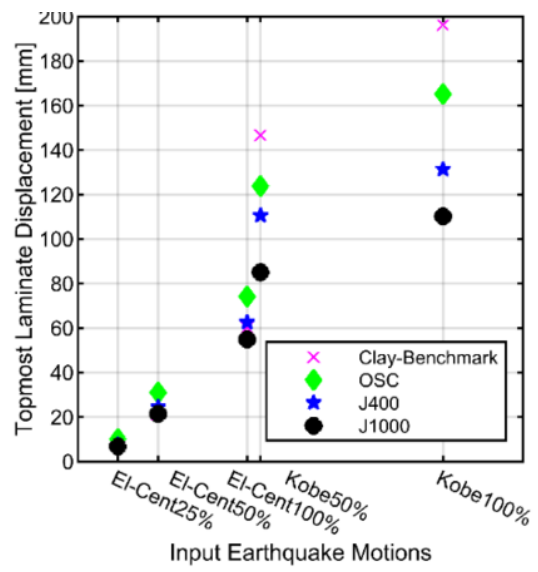

Figure 11. Top-most layer maximum lateral displacements for the experimental models under various seismic loading demands

Since the mass of individual soil samples housed in each layer of the laminar box can be calculated (by making use of the volume of each slice and then applying the density of soil in the volume), and since the acceleration response of each level is captured by accelerometers, the shear stress in between each laminate layer can be calculated. Further, since the lateral displacement of the individual laminates are captured individually by laser displacement sensors, the shear strains between neighboring laminate layers can be computed. Similar calculations have been used by many researchers to determine the hysteresis loops for the contained soil specimen in a laminar box type assembly $[45,46]$. 


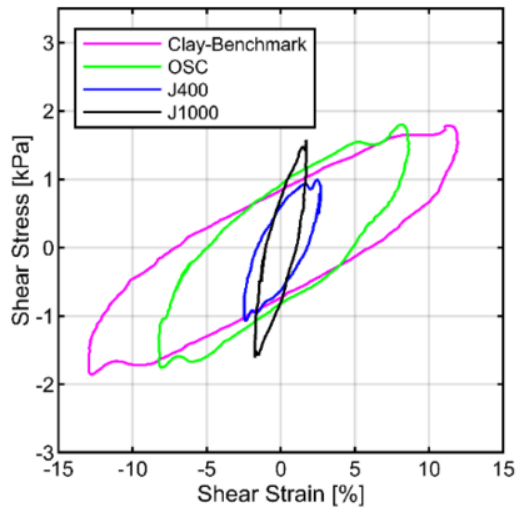

Figure 12. The hysteresis loops for the systems

The hysteresis loops depicted in Figure 12, correspond as an example to the 8th laminate movements and accelerations for all models. The reason for selecting the 8th laminate for the analysis is purely because this particular level of the assembly corresponds to the mid-height of the experimental setup. While all of the systems are uniquely different in their stiffnesses and it is to be expected that their mode shapes will be slightly different from one another, this particular place in the assembly is selected as a common comparison datum. Due to the differences in the modal shapes it could be argued that the selection of the comparison datum might have been biased for some systems where the points of maximum deflection coincide with 8th layer. Since it is assumed that $1 / 4$ th waveform is apparently seen on the physical models, it is not expected that these variations will cause significant differences. In light of the above explanations, it can be said that the GEC installation significantly increases the shear modulus of the soft soil body. In this particular case, the shear moduli for J1000, J400, OSC, and Benchmark-Clay models are 90.6, 39.6, 21.1, and $14.5 \mathrm{kPa}$, respectively.

During the tests, it was further observed that although extremely high amplitude earthquake recordings have been applied, no liquefaction was observed on the granular columns. This was considered to be due to the confinement provided by the geosynthetic encasements surrounding the granular material. This observation was made where the columns are under minimal vertical stress. Considering that the risk of liquefaction decreases with increased vertical stress, it can be easily stated that under the typical embankment load, the risk of liquefaction of the granular columns will be much less.

It has to be considered that all the other results have also been obtained with a minimal surcharge load. Without the full surcharge load of e.g. the later embankment, there is not a total activation of the ring forces in the geosynthetic encasement. It can be expected that the beneficial influence of the geosynthetic encasement would be even more pronounced in the case of a full embankment in place. 


\section{Case Studies on Transportation Infrastructure Supported by Granular Columns}

The wide versatility and ease of application of the GEC technique has made it possible to carry out many innovative foundation projects to be carried out for transportation applications. In the present paper three applications from Europe will be evaluated.

\subsection{Widening of A115 Motorway Embankment near Saarmund, Germany}

Almost three decades ago, a project to widen the A115 motorway (otherwise known as "Autobahn") south of Potsdam near Berlin in Germany was initiated with the ambition of expanding the road to six lanes. Over the planned alignment of the motorway embankment, a $300 \mathrm{~m}$ wide zone of lowlands comprising organic soils was posing a potential challenge for the construction project and the existing embankment was built using the bog blasting method.

As a solution to this challenge, $80 \mathrm{~cm}$ diameter GECs were installed on a grid to have a replacement ratio of $10 \%$ which means that the ratio of the native soil to column enhanced soil was 10/1. Horizontal and vertical inclinometers were installed during construction to monitor the deformation behavior of the embankment. Readings from two of the horizontal inclinometers have been taken for a significantly long period of time. Figure 13 shows a typical long-term time-settlement curve, most of the time inclusive of intensive "autobahn" traffic. As can be seen from Figure 13, postconstruction creep settlements are strongly reduced in relation to the predicted creep settlements of unimproved subsoil, approximately by $75 \%$. It is known that the road section performed perfectly well until today.

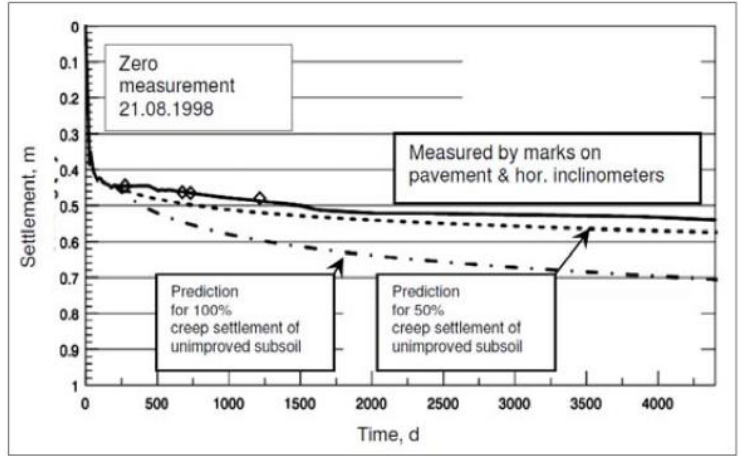

Figure 13. Time-settlement curves of a representative cross-section of A115 motorway near Saarmund

\subsection{High speed rail link Amsterdam-Paris, Netherlands, 2002}

The High speed $(300 \mathrm{~km} / \mathrm{h})$ rail link between Amsterdam and Paris was built in 2002 . Due to the high speed of the rail traffic requirements, the allowable deformations (such as total or differential settlements) on the project were very stringent. The route had to cross at Westrick-Breda for some hundreds of meters an old closed landfill which ceased to operate in early $1950 \mathrm{~s}$. To make matters worse, the waste had been never neither sorted, nor homogenized, nor compacted and had a significant degree of chemical contamination and was additionally mostly saturated. This resulted in very 
low and varying strength and deformation characteristics over the length of the route. The final optimized solution (Figure 14) comprised of a GEC foundation for the core embankment with a geogrid on top of the GECs. As material for the encasements PVA (Polyvinyl alcohol) was chosen due to two advantages: the high ring tensile modulus resulting in low settlements of the system and the high chemical resistance in a wide range of environments. The project was completed in only some months by the German contractor Möbius in 2002. Due to its high category, the project was accompanied by a measurement program. Some of the results are given in Figure 15. As can be seen the settlements in the non-supported area are about $0.5 \mathrm{~m}$ higher than in the GECsupported area (Figure 15, left), although the load on the non-supported zone below the shoulder of embankment is lower (roughly the half).

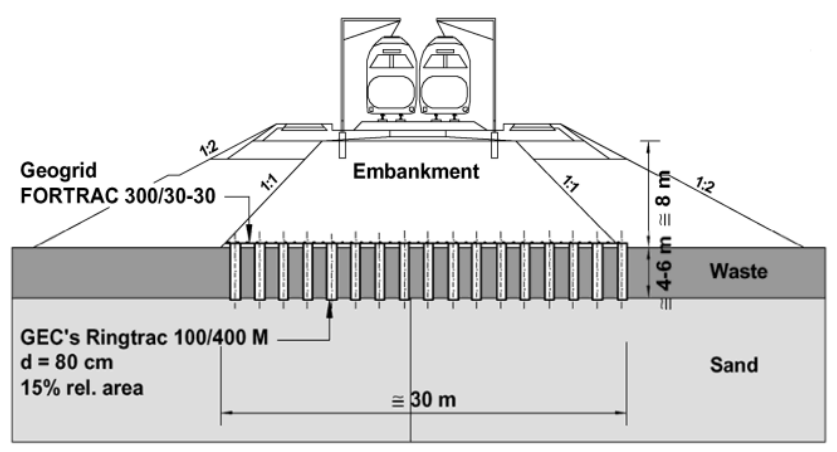

Figure 14. Typical cross-section at Westrick-Breda for the high-speed train Amsterdam-Paris
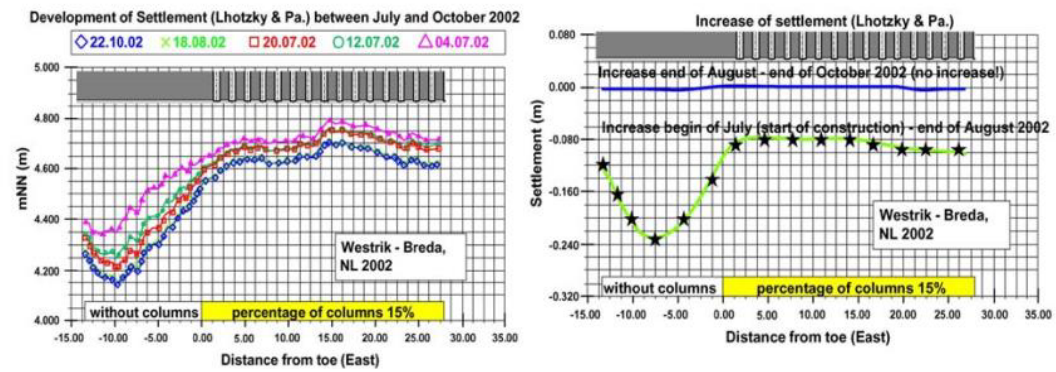

Figure 15. Westrick-Breda: total settlements (left) and increase of settlements (right)

Due to the ductile behavior of the GEC support, there is a "mild" settlement transition from supported to non-supported zone (Figure 15, left). Despite the inhomogeneity of the waste fill the max settlement difference across the GECsupported area is only ca. $0.05 \mathrm{~m}$. All settlements occurred in only 1.5 months (beginning of July-mid August); after that the system is completely stabilized and no further settlements occurred (Figure 15, right).

\subsection{Motorway A20 ("Autobahn") at Tessenitz, Germany, 1998}

The construction of the new Autobahn A20 in North-East Germany started at end of the 1990s. The route crosses also soft soil areas near the coast. This was the case at Tessenitz near Rostock. Due to these soil conditions, about half a kilometer of the road 
was founded on GECs (Figure 16). Since there is no speed limit on this Autobahn like in most of the Autobahns in Germany, there are high requirements regarding the postconstruction absolute and differential settlements under traffic. Among other arguments for the GEC-solution, one more aspect was taken into consideration, namely the longterm permeability combined with mechanical and filter stability due to the geotextile encasement of the GECs. This was important to create an optimal solution from the ecological point of view, because the installed GECs do not cause any disturbance in the natural groundwater regime. A specific point of the project was the strongly varying thickness of the soft organic clays across the embankment from ca. $8 \mathrm{~m}$ to ca. $15 \mathrm{~m}$. The embankment was temporarily overloaded for two months with a surcharge equivalent to the later heavy traffic to guarantee approximately zero settlements in the post-construction stage.

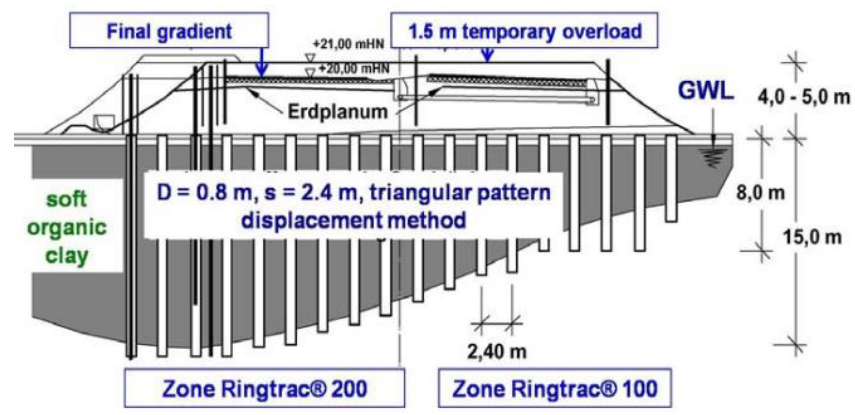

Figure 16. Motorway A20 at Tessenitz: typical cross section

\section{Conclusions}

As evidenced by the state of the art on the granular columns against unfavorable site and loading conditions, GECs emerge as an economic, safe, and environmentally friendly method of expanding and supporting transportation infrastructure. The main findings of the relevant research suggests the following:

- GECs allow the stone column construction in very soft soils successfully. They reduce the total settlement significantly and the differential settlement almost completely under self-weight and traffic loading conditions.

- GECs enhance the shear modulus of soft soils significantly and reduce the shear strains and lateral displacements of the soil body which means that the linear infrastructure built on or in the GEC enhanced soft soils are more likely to survive significant seismic activities.

- GEC installation significantly increases the shear resistance of the soft soils and therefore it may be instrumental in reducing or mitigating the edge failure and lateral spreading of the railway embankments constructed over soft soil layers.

- The settlement of the GEC enhanced unit cells are significantly reduced as opposed to OSC treated unit cells. It can be deducted that GEC application will significantly limit the total and differential settlement over the alignment of the railways which means that the vulnerability of the transport infrastructure due to seismic loading will be limited with GECs. 
- No liquefaction was observed in the granular stone columns, though extremely high amplitude earthquakes have been applied to the model tests.

- Case studies discussed herein highlight the main benefits of the GEC technology which are:

- GEC installation significantly reduces the creep deformations in the soil and projects incorporating GECs have stood the test of time and performed well for over 30 years.

- The GEC system is applicable to high speed railway applications over very soft soils with spatial variability of bearing capacity (such as closed landfills). Monitored performance of such systems suggest that once the stabilization settlements of the GEC enhanced foundation is complete, there is minimal to no settlements even in adverse sublayer conditions.

- $\quad$ The GEC system is adaptable to varying depth of sublayers and the overall performance of the system offers safe and reliable projects over the entire design life.

\section{References}

[1] Li S, et al., A Sustainable Transport Competitiveness Analysis of the China Railway Express in the Context of the Belt and Road Initiative. Sustainability, 2019. 11(10): p. 2896.

[2] Takagi K, Development of high-speed railways in China. Japan railway and transport review, 2011. 57: p. $36-41$

[3] Watson I, Ali A, and Bayyati A, Freight transport using high-speed railways. International Journal of Transport Development and Integration, 2019. 3(2): p. 103-116.

[4] Hughes JMO, Withers NJ, and Greenwood DA, A field trial of the reinforcing effect of a stone column in soil. Géotechnique, 1975. 25(1): p. 31-44.

[5] Malarvizhi SN and Ilamparuthi, Comparative Study on the Behavior of Encased Stone Column and Conventional Stone Column. Soils and Foundations, 2007. 47(5): p. 873-885.

[6] Rui R, et al., Experimental Investigation of Soil-Arching Development in Unreinforced and Geosynthetic-Reinforced Pile-Supported Embankments. Journal of Geotechnical and Geoenvironmental Engineering, 2019. 145(1): p. 04018103.

[7] EBGEO, Foundation Systems using Geosynthetic-encased Columns, in Recommendations for Design and Analysis of Earth Structures using Geosynthetic Reinforcements - EBGEO. 2012. p. 201-225.

[8] Van Eekelen S, Bezuijen A, and Van Tol A, Validation of analytical models for the design of basal reinforced piled embankments. Geotextiles and Geomembranes, 2015. 43(1): p. 56-81.

[9] Alexiew D, Kuster V, and Assinder P. An Introduction to Ground Improvement using Geotextile Encased Columns (GEC). in Proceedings of the Fifteenth African Regional Conference on Soil Mechanics and Geotechnical Engineering, Maputo, Mozambique (CD-ROM). 2011.

[10] Alexiew D, Brokemper D, and Lothspeich S, Geotextile encased columns (GEC): load capacity, geotextile selection and pre-design graphs, in Contemporary Issues in Foundation Engineering. 2005. p. $1-14$.

[11] Alexiew D, et al., Simplified estimation and graphs for pre-design of geosynthetic-encased sand or gravel columns as embankment foundation. IV Simpósio Brasileiro de Geossintéticos, 2003.

[12] Engelhardt K and Golding HC, Field testing to evaluate stone column performance in a seismic area. Géotechnique, 1975. 25(1): p. 61-69.

[13] Cengiz C and Guler E, Effects of Geosynthetic Encased Column Installation on the Seismic Response of Soft Clay Beds, in EuroGeo7, 7th European Geosynthetics Conference 2021, in press, IGS: Warsaw, Poland.

[14] Sivakumar V, et al., Triaxial tests on model sand columns in clay. Canadian Geotechnical Journal, 2004. 41(2): p. 299-312.

[15] Black J, et al., An Improved Experimental Test Set-up to Study the Performance of Granular Columns. Geotechnical Testing Journal, 2006. 29(3): p. 193-199.

[16] Sivakumar V, et al., The pressure distribution along stone columns in soft clay under consolidation and foundation loading. Géotechnique, 2011. 61(7): p. 613-620. 
[17] Hong YS, Wu CS, and Yu YS, Model tests on geotextile-encased granular columns under 1-g and undrained conditions. Geotextiles and Geomembranes, 2016. 44(1): p. 13-27.

[18] Black J, et al., Reinforced stone columns in weak deposits: laboratory model study. Journal of Geotechnical and Geoenvironmental Engineering, 2007. 133(9): p. 1154-1161.

[19] Wu CS and Hong YS, Laboratory tests on geosynthetic-encapsulated sand columns. Geotextiles and Geomembranes, 2009. 27(2): p. 107-120.

[20] Gu M, et al., Effects of geogrid encasement on lateral and vertical deformations of stone columns in model tests. Geosynthetics International, 2016. 23(2): p. 100-112.

[21] Debnath P and Dey AK, Bearing capacity of geogrid reinforced sand over encased stone columns in soft clay. Geotextiles and Geomembranes, 2017. 45(6): p. 653-664.

[22] Almeida MSS, et al., Behavior of Geotextile-Encased Granular Columns Supporting Test Embankment on Soft Deposit. Journal of Geotechnical and Geoenvironmental Engineering, 2015. 141(3): p. 04014116.

[23] Schnaid F, et al., Geotextile encased columns (GEC) used as pressure-relief system. Instrumented bridge abutment case study on soft soil. Geotextiles and Geomembranes, 2017. 45(3): p. 227-236.

[24] Yoo C and Lee D, Performance of geogrid-encased stone columns in soft ground: full-scale load tests. Geosynthetics International, 2012. 19(6): p. 480-490.

[25] Yoo C, Settlement behavior of embankment on geosynthetic-encased stone column installed soft ground - A numerical investigation. Geotextiles and Geomembranes, 2015. 43(6): p. 484-492.

[26] Indraratna B, et al., Coupled discrete element-finite difference method for analysing the loaddeformation behavior of a single stone column in soft soil. Computers and Geotechnics, 2015. 63: p. 267-278.

[27] Gu M, Han J, and Zhao M, Three-Dimensional DEM Analysis of Axially Loaded Geogrid-Encased Stone Column in Clay Bed. International Journal of Geomechanics, 2020. 20(3): p. 04019180.

[28] Almeida MSS, Hosseinpour I, and Riccio M, Performance of a geosynthetic-encased column (GEC) in soft ground: numerical and analytical studies. Geosynthetics International, 2013. 20(4): p. 252-262.

[29] Aboshi H, The "Compozer"-a method to improve characteristics of soft clays by inclusion of large diameter sand columns. 1979.

[30] Raithel M and Kempfert HG. Calculation models for dam foundations with geotextile coated sand columns. in ISRM International Symposium. 2000. International Society for Rock Mechanics and Rock Engineering.

[31] Pulko B, Majes B, and Logar J, Geosynthetic-encased stone columns: Analytical calculation model. Geotextiles and Geomembranes, 2011. 29(1): p. 29-39.

[32] Rowe PW, The stress-dilatancy relation for static equilibrium of an assembly of particles in contact. Proceedings of the Royal Society of London. Series A. Mathematical and Physical Sciences, 1962. 269(1339): p. 500-527.

[33] Mohapatra SR, Rajagopal K, and Sharma J, Direct shear tests on geosynthetic-encased granular columns. Geotextiles and Geomembranes, 2016. 44(3): p. 396-405.

[34] Mohapatra SR, Rajagopal K, and Sharma J, 3-Dimensional numerical modeling of geosyntheticencased granular columns. Geotextiles and Geomembranes, 2017. 45(3): p. 131-141.

[35] Cengiz C, Kilic IE, and Guler E, On the shear failure mode of granular column embedded unit cells subjected to static and cyclic shear loads. Geotextiles and Geomembranes, 2019. 47(2): p. 193-202.

[36] Abhishek SV, Rajyalakshmi K, and Madhav MR, Engineering of ground with granular piles: a critical review. International Journal of Geotechnical Engineering, 2016. 10(4): p. 337-357.

[37] Najjar SS, A State-of-the-Art Review of Stone/Sand-Column Reinforced Clay Systems. Geotechnical and Geological Engineering, 2013. 31(2): p. 355-386.

[38] Yoo C and Abbas Q, Laboratory investigation of the behavior of a geosynthetic encased stone column in sand under cyclic loading. Geotextiles and Geomembranes, 2020. 48(4): p. 431-442.

[39] Guler E. and Cengiz C, Theme Lecture: Performance of Ordinary and Geosynthetic Encased Stone Columns in Soft Clayey Soils under Seismic Loads, in VII International Conference on Earthquake Geotechnical Engineering. 2019: Rome, Italy.

[40] Cengiz C and Güler E, Seismic behavior of geosynthetic encased columns and ordinary stone columns. Geotextiles and Geomembranes, 2018. 46(1): p. 40-51.

[41] Cengiz C and Guler E, Shaking table tests on geosynthetic encased columns in soft clay. Geotextiles and Geomembranes, 2018. 46(6): p. 748-758.

[42] Cengiz C and Guler E, Load bearing and settlement characteristics of Geosynthetic Encased Columns under seismic loads. Soil Dynamics and Earthquake Engineering, 2020. 136: p. 106244.

[43] Cengiz C and Guler E, A laminar box apparatus for $1 \mathrm{~g}$ testing of granular columns embedded in soft clay. International Journal of Physical Modelling in Geotechnics, 2020. 20(1): p. 38-54.

[44] ISO, Geosynthetics - Wide-width tensile test, in ISO 10319:2015. 2015. 
[45] Tsai CC, Lin WC, and Chiou JS, Identification of dynamic soil properties through shaking table tests on a large saturated sand specimen in a laminar shear box. Soil Dynamics and Earthquake Engineering, 2016. 83: p. 59-68.

[46] Aghaei Araei A and Towhata I, Impact and cyclic shaking on loose sand properties in laminar box using gap sensors. Soil Dynamics and Earthquake Engineering, 2014. 66: p. 401-414. 